\title{
PARA ALÉM DA COMPARAÇÃO
}

Jürgen Kocka*

Resumo: Os méritos da abordagem comparativa para a história são inegáveis. A comparação ajuda a identificar questões, e a clarificar perfis de casos únicos. É indispensável para explicações causais e sua crítica. As comparações ajudam a criar um clima de história investigativa menos provinciana. Todavia, a história comparativa permanece minoritária. Muitos princípios acalentados da disciplina histórica proximidade das fontes, contexto e continuidade - algumas vezes estão em tensão com a abordagem comparativa. Mais recentemente, novas abordagens transnacionais - entangled history (história entrelaçada), histoire croisée (história cruzada) - desafiam historiadores comparativos em novas e interessantes perspectivas. Mas histoire comparée e histoire croisée podem ser compatíveis e precisam uma da outra.

Este comentário ${ }^{1}$ em primeiro lugar destaca a grande importância da comparação para a obtenção de visões inovadoras na história pela discussão das principais funções da abordagem comparativa aplicadas nos estudos históricos. Então, tenta responder a questão de por que, apesar disso, a comparação tem sido usualmente um fenômeno minoritário entre historiadores. Terceiro, discorrerá sobre os relativamente novos desafios que a história comparativa enfrenta hoje, e isso pode muito bem conduzir a comparação a um novo contexto. Umas poucas conclusões são oferecidas ao final. Para os propósitos deste comentário eu quero enfatizar que comparação em história significa discutir dois ou mais fenômenos históricos sistematicamente com respeito a suas similaridades e diferenças de modo a alcançar certos objetivos intelectuais. ${ }^{2}$

* Tradução de Maurício Pereira Gomes, mestre em História Cultural pela Universidade Federal de Santa Catarina (UFSC), e-mail: gomesupo@hotmail.com e de Cristina Scheibe Wolff, professora do Departamento de História da Universidade Federal de Santa Catarina (UFSC), bolsista de Produtividade de Pesquisa CNPq, e-mail: cristiwolff@gmail.com Artigo originalmente publicado sob o título Comparison and Beyond na Revista History and Theory, v. 42, n. 1, p. 39-44, fev. 2003. Reproduzido com permissão of Blackwell Publishing Ltd. Copyright 2003. 
Quais objetivos? Quais são, metodologicamente falando, os propósitos e funções da comparação em pesquisas históricas e apresentações? Eu proponho distinguir entre objetivos heurísticos, descritivos, analíticos e paradigmáticos.

Heuristicamente, a abordagem comparativa permite identificar questões e problemas que se pode perder, negligenciar, ou até mesmo não conceber. Para isso Marc Bloch deu um exemplo de sua própria pesquisa. Como historiador agrário ele tinha estudado processos de cercamento ${ }^{3}$ ingleses dos séculos XVI a XIX. A partir disso ele desenvolveu a suposição de que processos análogos devem ter ocorrido na França, embora ainda não confirmados por pesquisadores locais. Começando com essa questão Marc Bloch expõe sobre a Provença dos séculos quinze, dezesseis e dezessete, estabelecendo correlações através de mudanças não idênticas na estrutura da propriedade das terras e desta forma contribuiu para uma revisão abrangente da história da região. ${ }^{4}$ Esse foi um ato de transferência intelectual, baseado em suposições sobre similaridades entre Inglaterra e França, uma perspectiva produtiva tornada possível por comparações.

Descritivamente, as comparações históricas ajudam a esclarecer os perfis de casos singulares, frequentemente apenas de um caso, pelo(s) seu(s) contraste com outros. Muitos exemplos vêm à mente: por exemplo, todas as caracterizações do fenômeno histórico como "inicial" ou "tardio"; ou afirmações de particularidade, como a noção de um "Sonderweg Alemão" (excepcionalismo alemão) ou um "Excepcionalismo Americano"; e muitos outros exemplos - a partir de uma tipologia de processos regionais de industrialização na Europa Ocidental até a ideia de um caminho peculiar da modernização ocidental comparada com outras partes do mundo. A comparação nesse sentido é onipresente, e ainda desempenha um papel nos trabalhos históricos que não seriam classificados como comparativos no sentido pleno da palavra. Deve-se acrescentar que a comparação não somente ajuda a sustentar noções de particularidade, mas é também indispensável para desafiar e modificar tais noções. ${ }^{5}$

Analiticamente, a abordagem comparativa é indispensável para formular e responder questões causais. Este ponto tem sido comentado frequentemente com detalhes metodológicos e muitos exemplos. ${ }^{6}$ Atualmente a história mundial é um campo que se oferece para abordagens comparativas com objetivos causais, seja em relação à ascensão da ciência em diferentes civilizações ao longo dos séculos, seja com relação aos diferentes caminhos de mudanças e crescimento econômico, ou com relação a outros problemas. ${ }^{7}$ Max Weber foi pioneiro nesse tipo de comparação ambiciosa. Sewell e outros têm enfatizado que a comparação pode desempenhar o papel de um experimento indireto para facilitar "testes de hipóteses". Enquanto se pode ser cético quanto a essa afirmação (já que o provérbio ceteris paribus ${ }^{8}$ pode ser raramente apropriado em estudos históricos), não há dúvida que a comparação é indispensável 
para os historiadores que gostam de formular perguntas causais e fornecer respostas causais. Na mesma linha deve-se ressaltar que a necessária crítica de explicações causais dadas, incluindo a refutação de "pseudo-explicações" tanto as particulares como as generalizadoras, também precisa de comparações. ${ }^{9}$

Finalmente, apenas uma palavra sobre a função paradigmática da comparação. A esse respeito a comparação ajuda a distanciar-se um pouco do caso melhor conhecido da "própria história". Verfremdung é a palavra alemã. À luz das alternativas observáveis seu próprio desenvolvimento perde a auto evidência que poderia ter tido antes. Descobre-se que o caso com o qual se é mais familiar, é somente uma possibilidade entre outras. Frequentemente os historiadores estão relativamente concentrados nas histórias de seus países ou regiões. Por causa disso a comparação pode ter um efeito de "desprovincialização", uma liberação, um efeito de abrir os olhos, com consequências para a atmosfera e o estilo da profissão. Essa é uma contribuição da comparação que não deveria ser subestimada, mesmo hoje.

Esses pontos deveriam ser suficientes para nos lembrar das muitas vantagens que a comparação tem. Porque, no entanto, a história comparativa tem tido um status minoritário por um longo tempo e porque continua a ter tal status inclusive hoje? Há muitas razões práticas assim como razões relacionadas com as funções culturais e nacionais que a disciplina tem assumido ao longo dos séculos. Afinal, como uma grande disciplina a história emergiu em estreita interligação com a ascensão do Estado-Nação, ao menos no ocidente. Eu não estou lidando com esses obstáculos para os estudos comparativos nesse momento. Pelo contrário, quero discutir três sérias razões metodológicas que fazem a comparação difícil, três características que constituem uma certa tensão entre a abordagem comparativa e a tradição clássica da história como disciplina.

1. Quantos mais casos o estudo comparativo inclui, mais dependente ele se torna de uma literatura secundária, e torna-se mais difícil chegar perto das fontes e lê-las em sua língua original. Mas a proximidade com as fontes e o domínio de suas línguas tem se desenvolvido como um princípio fundamental do conhecimento histórico moderno à medida que este surgia, a partir do fim do século XVIII, por razões muito boas.

2. A abordagem comparativa pressupõe que as unidades de comparação podem ser separadas umas das outras. Não é nem a continuidade entre dois fenômenos, nem as influências mútuas entre eles que os constituem enquanto casos para comparação. Pelo contrário, eles são vistos como casos independentes que são reunidos analiticamente através de questionamentos por similaridades e diferenças entre eles. Em outras palavras, a comparação rompe continuidades, corta enredamentos, e interrompe o fluxo da narração. Mas a reconstrução de continuidades, a ênfase na interdependência assim como formas narrativas de apresentação, são elementos clássicos da história enquanto uma disciplina.

3. Não se pode comparar totalidades, no sentido de individualidades totalmente desenvolvidas. Pelo contrário, se compara em certos aspectos. 
Tem-se que decidir a respeito de quais pontos de vista, questões ou Erkenntnisinteressen se quer comparar dois ou mais casos. Quanto maior o número de casos incluídos, mais importante torna-se esta decisão seletiva em torno de pontos de vista, questões e problemas com base nos quais se quer comparar. Em outras palavras, comparação implica em seleção, abstração, e descontextualização em algum grau. Percebe-se isso logo quando se pensa em casos de múltiplas comparações. Qualquer um que tente comparar, digamos, vinte casos de industrialização regional ou padrões demográficos em quarenta cidades francesas em meados do século XIX, tem que isolar os objetos de comparação, as variáveis relevantes de seus contextos, em grande medida. Mas a ênfase no contexto, em imersão, no entrelaçamento, na Zusammenhang (relação) é preciosa e central para a história enquanto disciplina. Novamente há uma tensão entre a abordagem comparativa e alguns dos mais valorizados e considerados princípios dos estudos históricos, ao menos no Ocidente.

Estas são as principais razões metodológicas em virtude das quais abordagens comparativas não estiveram tradicionalmente no centro, mas na periferia da história enquanto disciplina. Isso também explica porque abordagens comparativas se tornaram muito mais populares e muito mais centrais uma vez que a história tornou-se uma ciência mais socialmente orientada nos anos 70 e $80 .{ }^{10}$

Mais recentemente o vento que bate na face dos historiadores comparativos tem se tornado ainda mais forte. Além das objeções mais tradicionais e convencionais que os historiadores possam ter contra comparações muito extensivas e rigorosas, há novas objeções contra as abordagens comparativas claras, desta vez do lado dos mais jovens, de uma forma interessante. Após o fim do conflito Leste-Oeste em torno de 1990 tanto os acelerados processos de internacionalização e os renovados debates sobre globalização começaram a mudar a maneira pela qual nós definimos questões históricas e exploramos problemas históricos. Como consequência há uma nova ênfase nas "histórias entrelaçadas", na "histoire croisée", na "Verflechtungsgeschichte", as quais vejo em tensão com princípios básicos da história comparativa. ${ }^{11}$

Há, felizmente, muito interesse agora em abordagens transnacionais para a história. As diferentes correntes de história global ou mundial são casos em evidência. Abordagens comparativas, comparações internacionais e interculturais, são somente um caminho para a realização desse crescente compromisso transnacional. Há outras formas por certo, por exemplo, estudos e interpretações usando teorias pós-coloniais. ${ }^{12}$ Esse caminho é menos interessado em similaridades e diferenças entre, por exemplo, Europa e o mundo Árabe, mas pelo contrário, nos processos de influência mútua, nas percepções recíprocas ou assimétricas, em processos cruzados de constituição um do outro. De certa forma, a história de ambos os lados é tomada como uma em vez de ser considerada como duas unidades em comparação. Fala-se de entrelaçamentos, 
interessa-se por troca de ideias, pessoas migrando, e comércio transnacional; mutuamente consideram-se imagens do outro, e se fala sobre mapeamentos mentais, aspectos de poder, subordinação e dominação. Dimensões culturais são geralmente centrais para tais abordagens. Partes Europeias e não Europeias do mundo, as civilizações ocidentais e não ocidentais são os temas prediletos para tais abordagens. "Histórias entrelaçadas" tornou-se uma frase chave, por exemplo, defendida pelo sociólogo-etnólogo Shalini Randeria. Outra variação desse tipo de abordagem tem sido chamada "histoire croisée", tal como uma histoire croisée (história cruzada) entre Alemanha e França no século XIX como propagado por Michael Werner, Bénédicte Zimmermann e Sandrine Kott. ${ }^{13}$

Estes são desenvolvimentos muito interessantes e promissores. Mas este tipo de abordagem transnacional vai além da comparação. Ou retrocede em relação às comparações? De qualquer modo a partir de um ponto de vista histórico-entrelaçado, a comparação parece um pouco mecanicista demais, um pouco analítica demais na medida em que separa a realidade em diferentes pedaços de modo a analisar, isto é, comparar os pedaços como unidades de comparação, enquanto seria necessário vê-los como uma totalidade, como uma teia de enredos, um "Zusammenhang" de Verflechtungen e relações. $\mathrm{Na}$ verdade, Espagne e Werner, que vieram dos estudos de literatura e cultura, e que abriram caminho para essa abordagem com relação ao desenvolvimento na Alemanha e na França, de modo muito precoce e eficaz, criticaram a abordagem comparativa. ${ }^{14}$ Nesse ponto eles têm muitos simpatizantes, particularmente entre historiadores culturais.

Certamente nem as forças embutidas no método histórico, nem o recente interesse em forças transculturais e transnacionais entrelaçadas devem ser tomadas como justificativa para a retratação da história comparativa. Proximidade das fontes e controle dos idiomas são imperativos importantes para a pesquisa histórica. Mas não devem ser tomados como desculpas para o excesso de especialização, nem devem impedir perspectivas amplas e interpretações abrangentes que historiadores possam oferecer nessa era global. As ênfases na continuidade e no contexto são indispensáveis para o trabalho dos historiadores e sua caracterização. Mas, por outro lado, a continuidade é apenas um princípio orientador da reconstrução histórica, dentre outros, e enquanto os historiadores têm que considerar o contexto seriamente, suas operações intelectuais são sempre seletivas, pontos de vista relacionados e, neste sentido, analíticos, eles nunca reconstroem totalidades integrais.

Consequentemente, abordagens comparativas somente enfatizam e tornam particularmente manifesto o que está implícito em qualquer tipo de trabalho histórico: um forte componente seletivo e construtivo. A história comparada força seus praticantes a explicitamente refletir sobre essas premissas epistemológicas de seus trabalhos, enquanto essas premissas são frequentemente somente implícitas em outras abordagens. $\mathrm{O}$ novo interesse 
nos entrelaçamentos transnacionais é bem vindo e promissor. No entanto, tal interesse não deve se distanciar, mas deve incorporar rigorosas comparações, as quais continuam particularmente indispensáveis para os estudos históricos. com alcance global, se não quiserem tornar-se meramente especulativos ou folhetinescos.

Mas os historiadores comparativos deveriam reagir às antigas advertências e aos novos desafios de uma forma produtiva. Usualmente eles limitarão o número de casos em comparação de modo a ter suficientes contextos em consideração. Mais importante, eles podem e devem incorporar elementos da abordagem da "história entrelaçada" para o delineamento comparativo de suas pesquisas. Certamente, o ato de comparação pressupõe a separação analítica dos casos para serem comparados. Mas isso não significa ignorar ou negligenciar as interelações entre esses casos (se e na medida em que eles existiram). Pelo contrário, tais interelações deveriam tornar-se parte do quadro comparativo, analisando-os como fatores que levaram a similaridades ou diferenças, convergências ou diferenças entre os casos comparados.

Isto foi feito antes. Tome a comparação clássica de Alexander Gerschenkron da industrialização Europeia como um exemplo. Ele, de certa forma, considerou a industrialização Europeia como um todo. Ao mesmo tempo ele comparou suas partes ou segmentos, isto é, processos de industrialização dentro dos diferentes países. Ele deu muito peso para as interelações entre eles, por exemplo, para a exportação e a importação de capital, trabalho, e ideias, bem como para processos de percepção, imitação, transferências, e rejeição entre as industrializações em diferentes países Europeus. E ele mostrou que algumas dessas interelações contribuíram para maior similaridade enquanto outras levaram a importantes diferenças entre padrões nacionais de industrialização na Europa. ${ }^{15}$ Philipp Ther investiga as origens, programas, organizações e apoio público para casas de ópera no século XIX no centro do Leste Europeu e Alemanha. Ao analisar as diferenças e similaridades ele também mostra como eles percebiam e influenciaram uns aos outros - todos eles elementos de uma abrangente cultura da Europa Central. ${ }^{16}$

Muitos outros exemplos poderiam ser dados para demonstrar que é possível e desejável tanto tratar o fenômeno histórico como unidades em comparação e, ao mesmo tempo, como componentes de um todo maior. As abordagens da História comparativa e da "história entrelaçada" são diferentes modos de reconstrução histórica. Há uma tensão entre elas, mas elas não são incompatíveis. Pode-se tentar analisar em termos comparativos e contar uma história, todavia. Não é necessário escolher entre histoire comparée e a histoire croisée. O objetivo é combiná-las.

Friedrich-Meinecke-Institut

Berlin 


\section{NOTAS}

${ }^{1}$ Apresentado no painel "Problemas da Explicação Comparada" na Quarta Conferência de História das Ciências Sociais em Haia, 2 de março de 2002.

${ }^{2}$ Para outros aspectos e pesquisas de literatura cf. KOCKA, Jürgen. "The uses of Comparative History”. In: BJÖRK, Ragnar; MOLIN, Karl. (Eds.). Societies Made up of History: Essays in Historiography, Intellectual History, Professionalisation, Historical Social Theory, \& Proto-Industrialisation. Edsbruck-Sweden: Akademitryck AB, 1996. p 197-209. HAUPT, Heinz-Gerhard; KOCKA, Jürgen. (Eds.). Geschichte und Vergleich: Ansätze und Ergebnisse international vergleichender Geschichtsschreibung. Frankfurt/New York: Campus, 1996.; KOCKA, Jürgen. "Storia comparata". In: Enciclopedia delle scienze sociali. Rome: Istituto della Enciclopedia italiana, 1998. v. 8, S. 389-396; HAUPT, Heinz-Gerhard. "Comparative History". In: International Encyclopedia of the Social and Behavioral Sciences. Amsterdam/ New York: Elsevier, 2001. v. 4, 2397-2403; KAELBLE, Hartmut. Der historische Vergleich: Eine Einführung zun 19, und 20. Jahrhundert. Frankfurt/New York: Campus Verlag, 1999.

${ }^{3}$ Uso de cercas para delimitar áreas agrícolas que na Inglaterra implicou no alijamento dos camponeses do uso de terras comuns e sua consequente migração para áreas urbanas (N. dos T.).

${ }^{4}$ BLOCH Marc. Pour une histoire compare des societies européenes. Mélanges historiques (1928). Paris: École des Hautes Études en Sciences Sociales, v. 1, p. 16-40, 1983.

${ }^{5} \mathrm{O}$ debate e pesquisa sobre as questões de um "German Sonderweg" podem servir como um exemplo. Cf. KOCKA Jürgen, Asymmetrical Historical Comparison: The case of the German Sonderweg. History and Theory, n. 38, p. 40-51, 1999.

${ }^{6}$ Cf. SEWELL, Willian H.. "Marc Bloch and the Logic of Comparative History", History and Theory 6 (1967), 2008-218; A. A. van den Braembussche, "Historical Explanation and Comparative Method: Towards a Theory of the History of Society", History and Theory 28 (1989), 2-24.

${ }^{7}$ Para uma visão recente desses debates ver Gale Stokes, "The Fates of Human Societies: A Review of Recent Macrohistories", American Historical Review 106 (2001), 508-525.

${ }^{8}$ Expressão latina que remete para a noção de que ficam mantidas inalteradas todas as demais coisas do universo objeto de estudo (N. dos T.)

${ }^{9}$ Novamente Bloch tem dado exemplos. Cf. nota 5 acima.

${ }^{10}$ Com base em um levantamento exaustivo Hartmut Kaelble identifica a década de 80 como, quantitativamente vista, a fase de avanço da história comparativa na Europa. Hartmut Kaelble, "Vergleichende Sozialgeschichte dês 19. Und 20. Jahrhunderts: Forschungen europäischer Historiker", em Haupt and Kocka, Eds. Geschichte und Vergleich, 97.

${ }^{11}$ Cf. Johannes Paulmann, "Internationaler Vergleich und interkultureller Transfer: Zwei Forschungsansätze zur europäischen Geschichte des 18. Bis 20. Jahrhuntderts", Historische Zeitschrift 267 (1998), 649-685; Globalization in World History, ed. Anthony G. Hopkins (London: Pimlico, 2002).

${ }^{12}$ Cf. Robert J. C. Young. Postcolonialism: Na Historical Introducitio (Oxford e Malden, Mass: Blackwell Publishers, 2001).

${ }^{13}$ Sanjay Subrahmanyam, "Connected Histories: Notes toward a Reconfiguration of Early Modern Eurasia", Modern Asian Studies 31 (1997), 735-762; Shalini Randeria, "Geteilte Geschichte und verwobene Moderne", em Zukunftsentwürfe: Ideen für eine Kultur der Veränderung, ed. Jörn Rüsen et al. (Frankfurt: Campus, 1999), 87-96; Le travail et la 
nation: Histoire croisée de la France et de l'Allemangne, ed. Bénédicte Zimmermann et al, (Paris, Maison des sciences de l'homme, 1999); Jürgen Osterhammel, "Transnationale Gesellschaftsgeschichte: Erweiterung oder Alternative?", Geschichte und Gesellschaft 27 (2001), 464-479; Sebastian Conrad, "Doppelte Marginalisierung: Plädoyer für eine transnationale Perspektive auf die deutsche Geschichte" Geschichte und Gesellschaft 28 (2002), 145-169; Emma Rothschild, "Globalization and the Return of History", Foreign Policy (Summer 1999), 106-116.

${ }^{14}$ Transferts: le relations interculturelles dans l'espace franco-allemand (XVIIIe ET XIXe siècle), Ed. Michel Espagne and Michael Werner (Paris, Editions Recherche sur lês civilisations, 1988).

${ }^{15}$ A. Gerschenkron, Economic Backwardness in Historical Perspective (Cambridge, Mass.: Belknap Press of Havard University Press, 1962), 5-51, 353-364.

${ }^{16}$ Philipp Ther, "Geschichte und Nation im Musiktheater Deutsclands und Ostmitteleuropas", Zeitschrift Geschichtswissenschaft 50 (2002), p. 119-140.

Tradução recebida em setembro de 2013. Aceita em julho de 2014. 